\title{
HEPATIC CLEARANCE AND Lm OF GALACTOSE IN NORMAL AND CIRRHOTIC SUBJECTS
}

\author{
Cesare Dal Palù, M.D. \\ Piero SPANDri, M.D. \\ RENZO ZuIN, M.D.
}

Clinica Medica Generale e Terapia Medica, University of Padua, Italy

SLIGHT galactose intolerance, clinically latent, has recently been suspected as being of possible importance in the pathogenesis of some cases of juvenile cirrhosis. In order to check this hypothesis, we considered that the maximum hepatic removal capacity for galactose, measured according to the technique described by Waldstein and colleagues in 1960, would be the most suitable test for our purpose. The results we obtained, however, both in normal subjects and in cirrhotic patients were so inconsistent as to make us reconsider the whole question of galactose maximum removal.

\section{Material and Methods}

Twenty-four control patients, all negative for hepatic disease, and 26 patients affected by liver cirrhosis were the subjects of our study. All were in a basal condition after 12 hours' fasting. The constant infusions of galactose, $40 \%$ in saline at variable rates from 100 to $1000 \mathrm{mg}$./min., were given by a Sigmamotor pump.

In most of the patients two or three rates of infusion were carried out without any interval. In any instance from 30 to 80 mins were allowed for equilibration. When the first or the second rate of infusion was high, a priming injection of 10-40 g. of $40 \%$ galactose was given. In those patients who received infusion rates over $800 \mathrm{mg}$./min., only a single infusion was given. No reactions were seen except for a moderate fever (up to $38^{\circ} \mathrm{C}$ ) in cirrhotic patients which lasted for a few hours.

Clearance periods lasted for an average of 20 mins (from 15 to $35 \mathrm{mins}$ ) during which four samples of heparinized blood were collected from an 18 gauge needle inserted in an antecubital vein of the opposite arm. Urines were collected through a urethral catheter at the beginning and at the end of each clearance period. The patient drank $500-1000 \mathrm{ml}$. of water in $30-45$ mins at the beginning of each infusion period so as to ensure an adequate urinary output. Blood and urine were analysed for galactose by the Nelson-Somogyi hexose method, glucose being previously eliminated by incubation with glucose oxidase (Boehringer).

The aim of this constant infusion method is to attain a constant concentration of galactose in the blood. The exact removal rate within the body can then be calculated, this being the difference between the rate of infusion and the average urine excretion. The importance of attaining equilibrium is all the more evident when using galactose because this hexose is eventually distributed widely through the organism, so that even minor variations of its plasma concentration may correspond to considerable retention or removal of the hexose from the body. Furthermore, since it is difficult to determine the galactose distribution space in each patient, correction of the apparent removal rate is practically impossible, even if the plasma concentration is increasing or decreasing only slowly during the clearance period. There were eight cases in which this occurred in the present study and these have therefore been excluded from the analysis. Tygstrup and Winkler (1954) found that a constant plasma level of galactose is only obtained when the infusion rates are below 300 $\mathrm{mg} / \mathrm{min}$ in normals and below $200 \mathrm{mg} / \mathrm{min}$ in cirrhotic patients. We were unable to confirm this observation: this is in agreement with Waldstein's experience. The reason for the discrepancy is not clear.

In all other cases the plasma concentrations, though not entirely constant, varied only slightly from the average, so that an arithmetic mean could be drawn. Deviation of plasma concentrations from the average was higher in our experience than in Waldstein's: $1-5 \mathrm{mg}$. $100 \mathrm{ml}$. for equilibrium concentrations up to $50 \mathrm{mg} . / 100 \mathrm{ml}$.; $1-15 \mathrm{mg} . / 100 \mathrm{ml}$. up to $200 \mathrm{mg}$. $/ 100 \mathrm{ml}$.; $10-20 \mathrm{mg} . / 100 \mathrm{ml}$. above $300 \mathrm{mg} . / 100 \mathrm{ml}$. Deviations were apparently higher in cirrhotic patients than in controls, but this was due to the fact that their plasma equilibrium was usually higher.

\section{Results}

The results obtained in the control subjects have been compared with those reported by Waldstein, Greenburg, Biggs and Corn (1960), these being the only workers, as far as we know, who have succeeded in determining the maximum liver galactose removal by means of a continuous infusion in man.

The equilibrium concentration tends to increase regularly together with the rate of infusion (Fig. 1). The correlation is quite close, as is shown by the statistical analysis of the results. As far as the ratio between the rate of infusion and the calculated body removal rate is concerned, there are two points to be noted. First, there is a close correlation between the two parameters. Secondly, when the infusion rate of galactose is increased to as much as $1 \mathrm{~g}$./ $\mathrm{min}$, the apparent removal rate exceeds 600 $\mathrm{mg} / \mathrm{min}$, and a maximum removal rate is not clearly attained (Fig. 2).

This does not actually mean that the body 


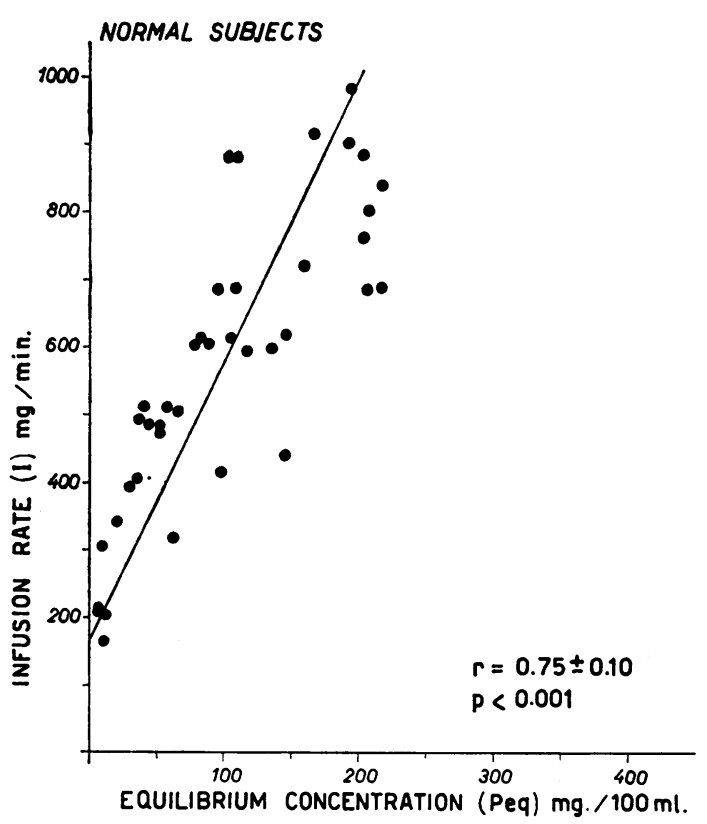

FIG. 1.

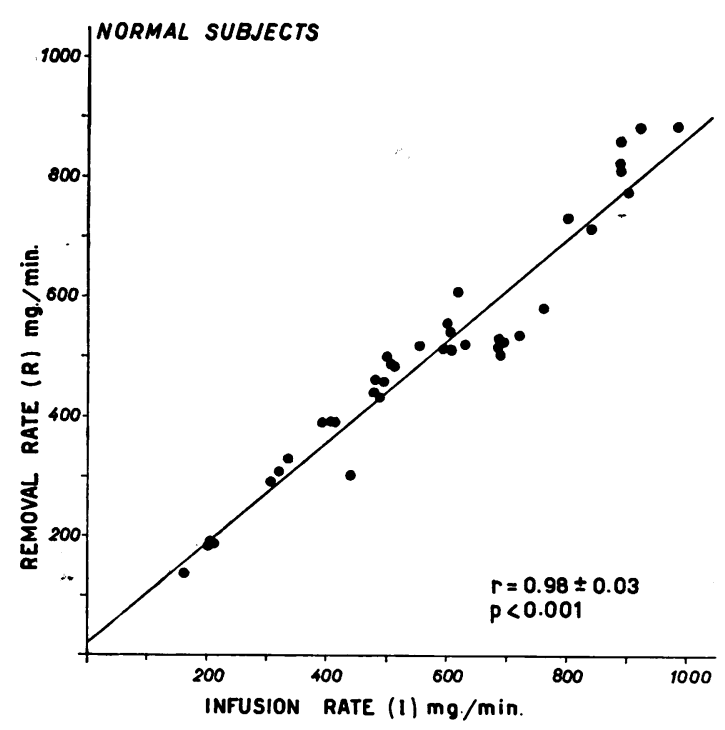

Fig. 2.

removal rate is entirely the result of hepatic cell activity. The values of calculated "hepatic" clearance (better, "intracorporeal" clearance) are shown in Fig. 3. When plotted against equilibrium concentration, an inverse relationship between the two parameters is found and the shape of the designed curve is expotential. The fact that maximal clearance values largely

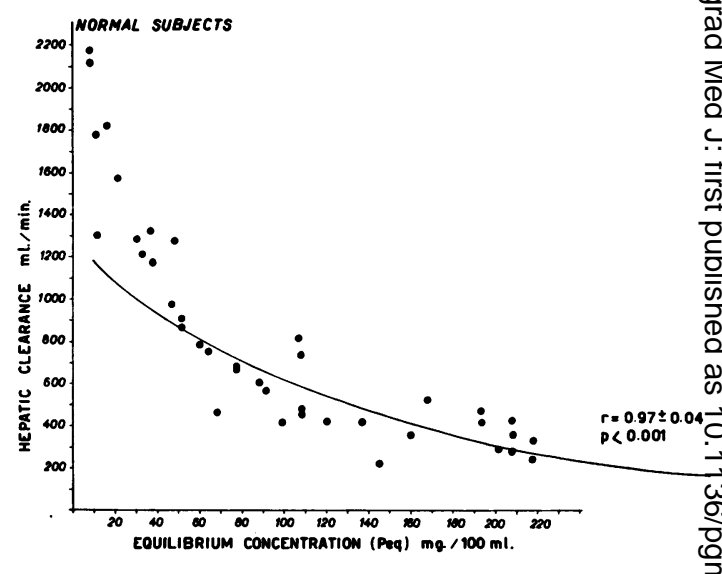

FiG. 3.

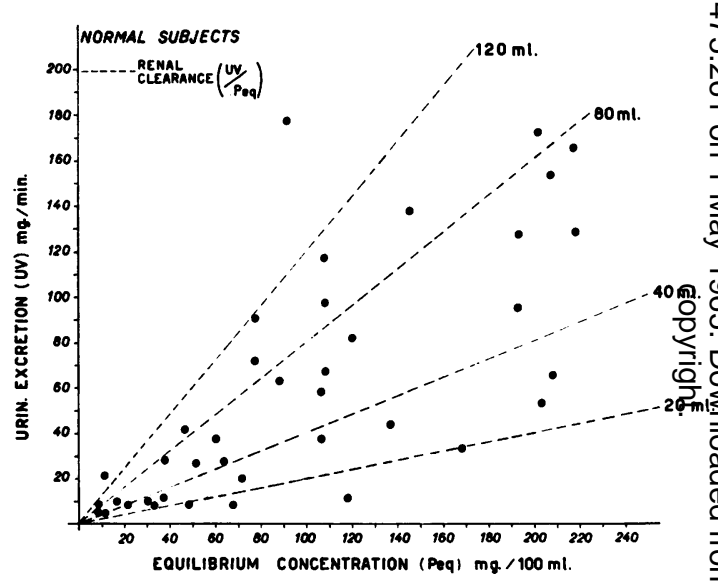

FIG. 4.

exceed the ones normally obtained for livep blood flow, indirectly confirms the existence of a constant amount of extrahepatic removal? even at levels of equilibrium below $30 \mathrm{mg}$. $100 \mathrm{ml}$. It seems impossible therefore to use galactose clearance to determine the liver blood flow without hepatic vein catheterisation, as suggested by Tybjaerg-Hansen, Tygstrup and Winkler (1954).

The renal threshold for galactose is ex- N tremely low, since the hexose appears in the urine at plasma concentrations of $10-20 \mathrm{mg} . / 100 \mathrm{~N}$ $\mathrm{ml}$. The urinary output tends to increase with increasing plasma concentrations, though the correlation between the two is rather poof? (Fig. 4). A certain correlation with diuresis is to be noted though it is not close enough to affirm that galactosuria is highly dependent on the rate of urine flow, as claimed by Domingues, and Pomerene (1944). No evidence for a re- $\frac{?}{\mathrm{D}}$ 


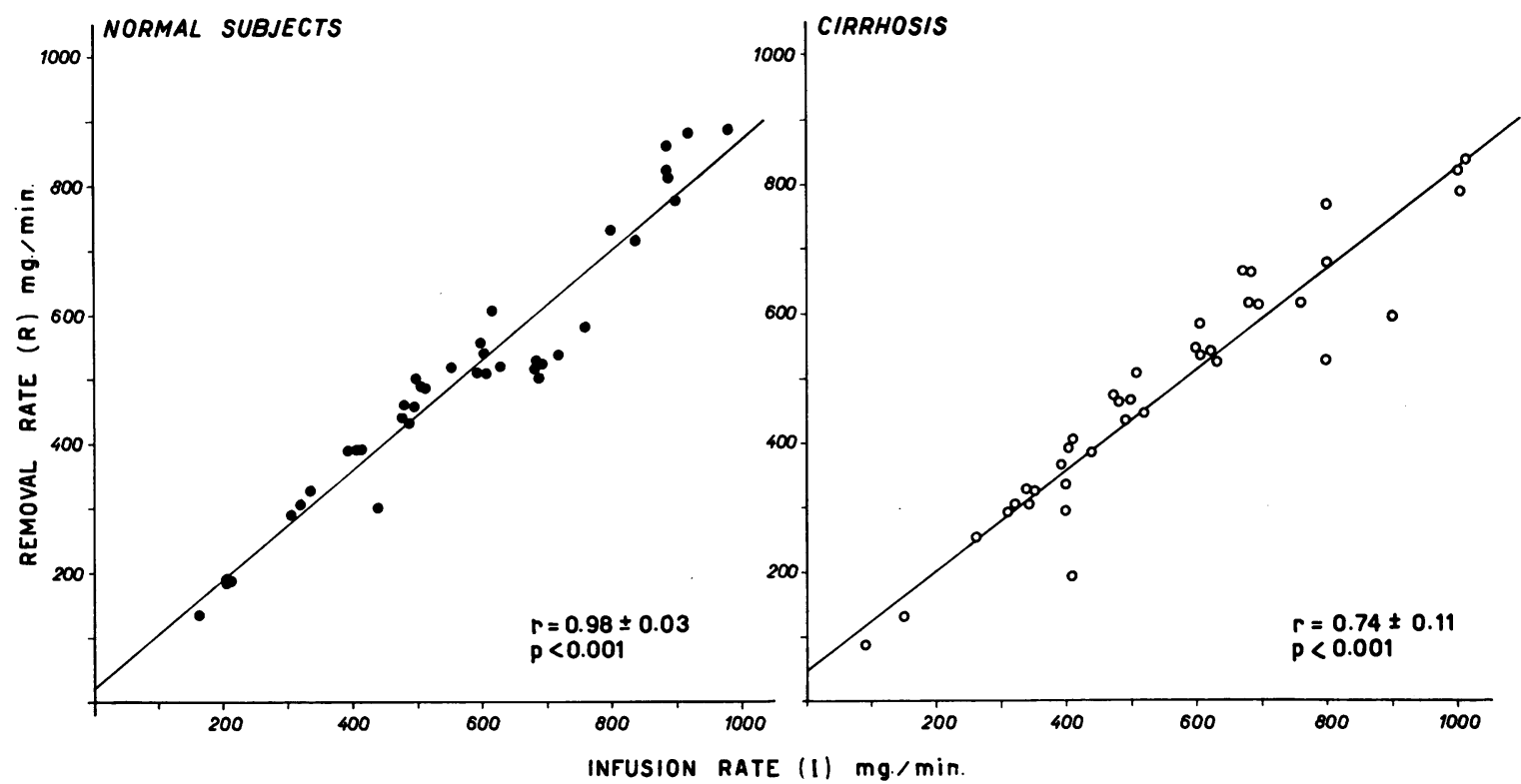

Fig. 5

absorption tubular maximum (Tm) was found within the range of plasma concentrations studied (up to $220 \mathrm{mg} / 100 \mathrm{ml}$ ). This is shown by the renal clearance values which only in a few cases equal the glomerular filtration rate. In this connection our experience is completely different from Waldstein's, who reports galactose renal clearances varying from 80 to 120 $\mathrm{ml} / \mathrm{min}$. Most of our values fell between 30 and $70 \mathrm{ml} . / \mathrm{min}$.

The results obtained in the 24 cirrhotic patients who were given the same doses of infused galactose were also rather surprising. The apparent body removal rate is only slightly lower than in the control patients (Fig. 5). A definite difference between the two groups appears only at rates of infusion above 700 $\mathrm{mg}$./min. "Hepatic" clearance is inversely proportional to equilibrium concentrations, and its values are only slightly higher in controls than in cirrhotic patients (Fig. 6). Equilibrium plasma concentrations are similar in the two groups of patients at rates of infusion up to $400 \mathrm{mg}$. $/ \mathrm{min}$. They begin to differ with loads of $4-500 \mathrm{mg} / \mathrm{min}$, being higher in cirrhotic patients. With infusions over $700 \mathrm{mg}$./min. there is practically no overlapping between the two groups (Fig. 7). The volume of distribution of galactose in cirrhotic patients being often larger than in normals, we can argue from these data that cirrhotic patients retain a larger quantity of infused galactose.
The rate of urinary loss of galactose is slightly greater in controls than in cirrhotic patients. As the plasma concentrations are higher, the renal clearance values are definitely lower in cirrhotic patients than in normals. This may be due to the reduction of the glomerular filtration rate which is so frequently observed in patients with decompensated cirrhosis.

\section{Discussion}

The present results neither substantiate the existence of a total body maximum removal rate for galactose in man, nor reveal a clearcut difference between normals and cirrhotic patients. These surprising findings may be explained in two different ways. Firstly, it is possible that the maximum hepatic capacity for removal of galactose is so high as not to be saturated at the infusion rates used in the present studies: in any case it would be definitely higher than $550 \mathrm{mg} . / \mathrm{min}$. It follows from this also that the cirrhotic liver must be retaining its capacity for metabolizing galactose, since no definite difference from the normal could be demonstrated with the rates infused. Such an explanation is supported by the studies of Bollman, Mann and Power (1935) which showed that the disappearance of injected galactose from the blood was normal in dogs made cirrhotic or after a $50-70 \%$ hepatectomy. It is not in agreement, however, with 


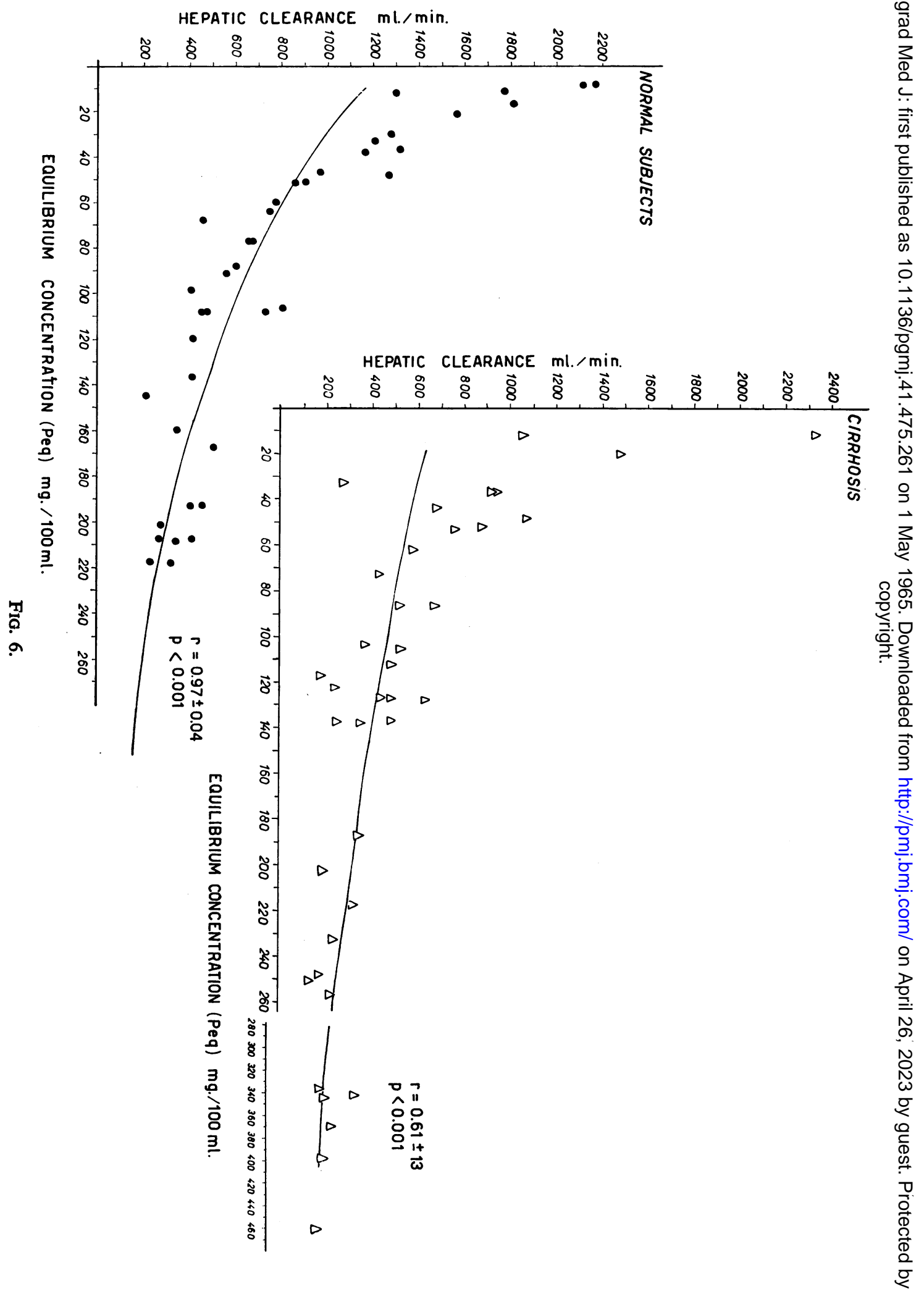




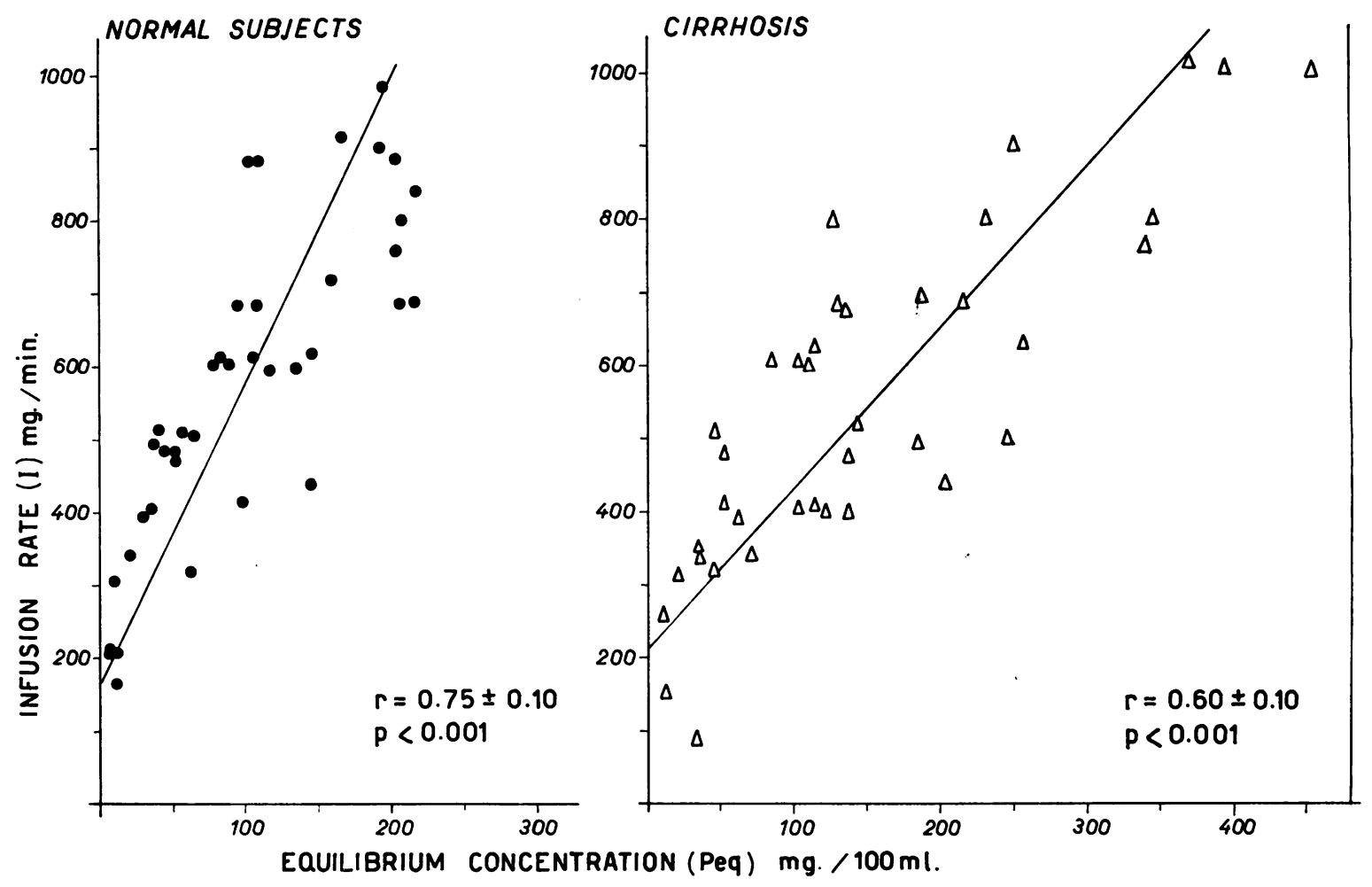

FIG. 7.

other previous findings, namely that the middle section of a galactose blood-time curve after a single intravenous administration is rectilinear (Tygstrup, 1963) and that the same curve in cirrhotic patients is slower than in normals even when determinations are made after a constant infusion lasting 60 mins. (Labò and colleagues, 1959).

The second possibility would be that the disappearance of galactose from the blood during intravenous infusion is dependent not only on hepatic and renal removal, but also on the presence of other mechanisms which therefore make it impossible to measure the liver removal maximum. For instance it is possible that galactose is being distributed into further and further compartments of the extracellular space and also into cells throughout the body during the whole infusion period. This is particularly likely to be true in cirrhotic patients whose extracellular space is so often increased. Indeed, in one of our patients the galactose concentration in ascitic fluid one hour after the beginning of infusion was only $100 \mathrm{mg}$. $/ 100 \mathrm{ml}$. whereas the plasma concentration was $200 \mathrm{mg} . / 100 \mathrm{ml}$. As far as the entry of galactose into the cells is concerned, this may be facilitated by the high plasma concentrations we have obtained, both directly and through the stimulation of insulin secretion as has been suggested by several other workers, (Levine, Goldstein, Huddlestun and Klein, 1950; Wick and Drury, 1953; Papper, Saxon and Alpert, 1957). This hypothesis may find support in the difference that we ourselves have found in two cases between the galactose concentration in arterial blood and in blood sampled from the superior and inferior venae cavae.

It might be thought that the attainment of an equilibrium galactose concentration in the plasma of our patients would be evidence against the concept suggested of a continuous diffusion of the hexose in the body spaces and cells. Berger and Farber (1948), however, have actually demonstrated, during measurements of PAH Tm by the constant infusion method, that equilibrium may be a mere illusion only, due to the wide distribution space of the infused material. It should be pointed out also that, if this second possibility is true, then the disappearance curves of galactose from blood after prolonged infusions may also be distorted by 


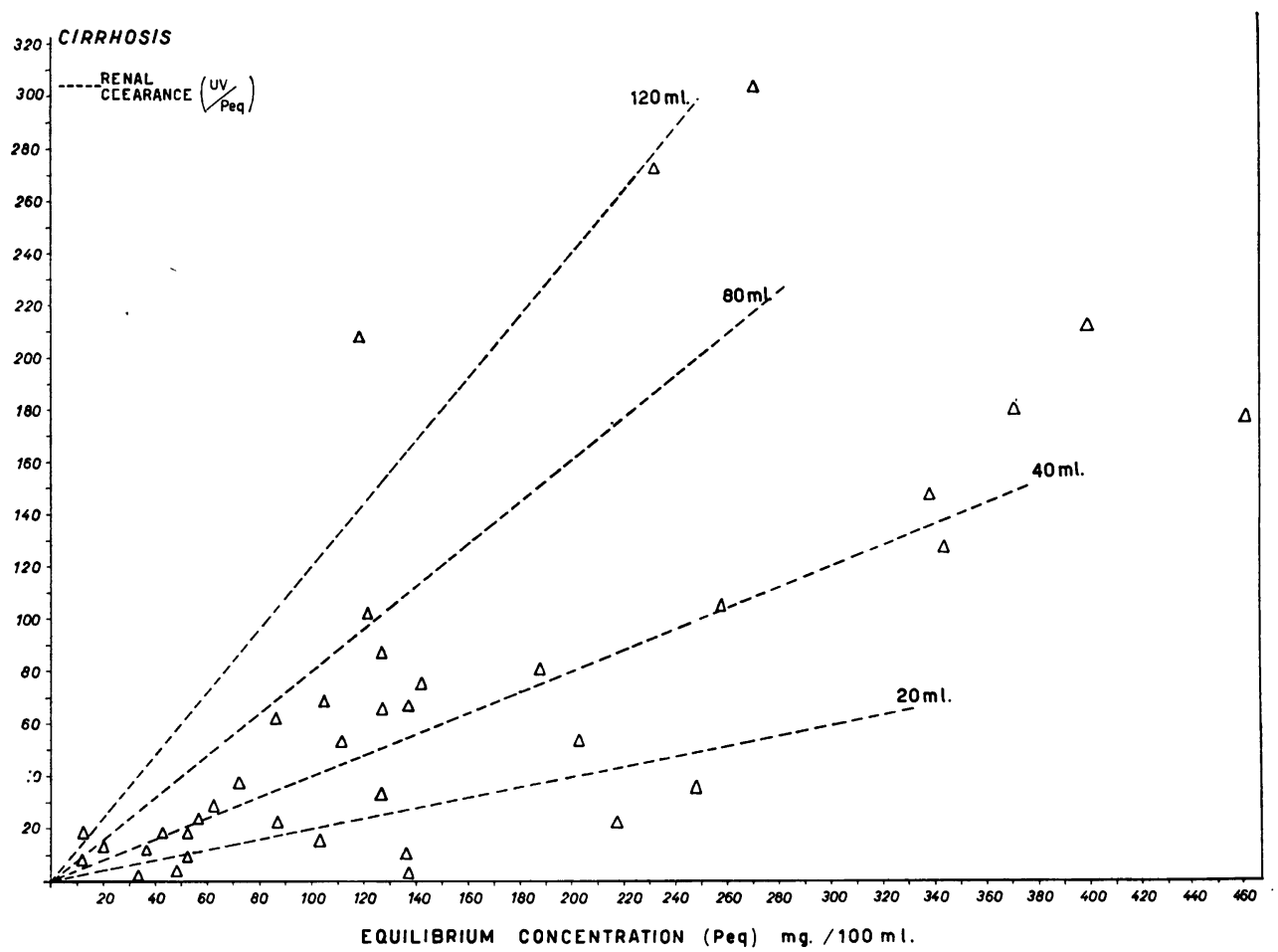

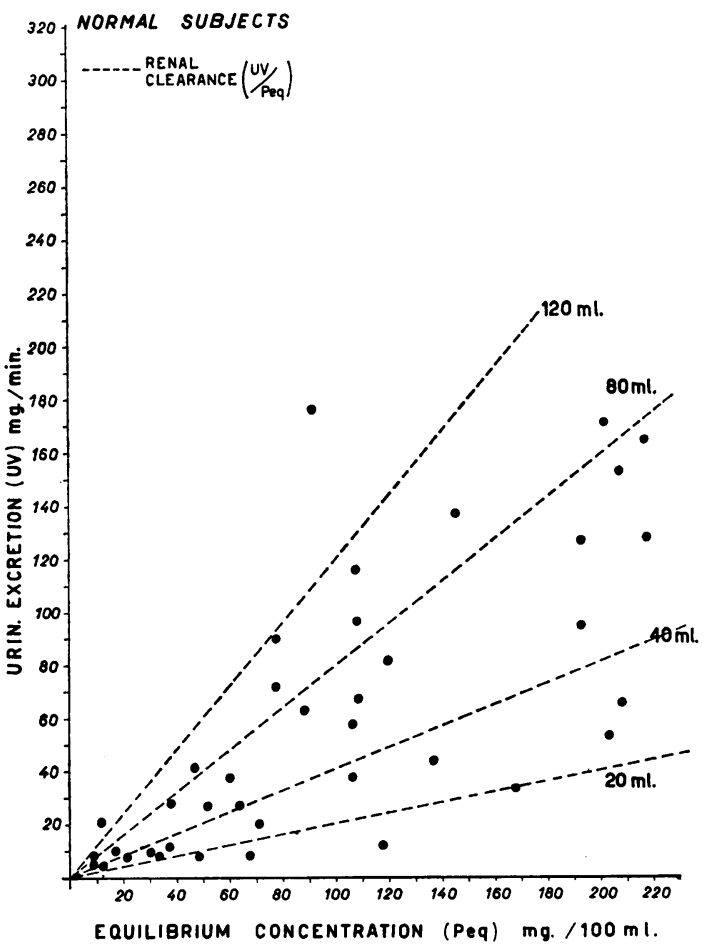

FIG. 8 the release of galactose from the cells and extracellular spaces into the blood.

In conclusion, it is clear that $\mathrm{Lm}$ for galactose cannot be determined by a continuous infusion method, even using high doses of this hexose: $\overrightarrow{\vec{B}}$ even with the latter this method does not enables any marked difference to be detected between the capacity of cirrhotic patients and that of normal subjects to metabolize galactose.

\section{REFERENCES}

Berger, E., and FARBER, S. (1948): Comparison of thei Constant Infusion and Urine Collection Techniques? for the Measurement of Renal Function, J. clin. Invest., 27. 710.

Bollman, J. L., ManN, F. C., and Power, M. H (1935): The Utilization of Galactose Followingo Complete Removal of the Liver, Amer. J. Physiol., 3, 483.

Dominguez, R., and Pomerene, E. (1944): (Cited by Tygstrup and Winkler), Amer. J. Physiol., 141, 368 N

Labò, C., Pedrazzi, F., and Franco, T. (1959): In Galattosio e il suo Interesse Clinico, Ed. Steb Bologna.

Levine, R., Goldstein, M. S., Huddlestun, B. and KLeIN, S. P. (1950): Action of Insulin on the Permeability of Cells to Free Hexoses, as Studied? by its Effect on the Distribution of Galactose? Amer. J. Physiol., 163, 70.

NELSON, W. (1944): A Photometric Adaptation of the Somogyi Method for the Determination of Glucose J. biol. Chem., 153, 375 . 
Papper, S., Saxon, L., and Alpert, H. C. (1957): The Effects of Cortisone on the Galactose Tolerance Tests of Normal Man, J. Lab. clin. Med., 50, 385.

Tybuaerg-Hansen, A., Tygstrup, N., and Winkler, K. (1954): Determination of the Hepatic Blood Flow by Galactose, Dan. med. Bull., 1, 146.

TYgSTRUP, N., and WinkLER, K. (1954): Kinetics of Galactose Elimination, Acta. physiol. scand., 32, 4.

TYGSTRUP, N. (1963): Determination of the Hepatic Galactose Elimination Capacity after a Single
Intravenous Injection in Man, Acta. physiol. scand., 58, 162.

WALDSTEIN, S. S., and ARCilla, R. A. (1954): Measurement of Hepatic Blood Flow by Clearance Methods, Amer. J. dig. Dis., 3, 2.

Waldstein, S. S., Greenburg, L. A., Biggs, A. D., and CORN, L. (1960): Demonstration of Hepatic Maximum Removal Capacity $(\mathrm{Lm})$ for Galactose in Humans, J. Lab. clin. Med., 55, 462.

WICK, A. N., and DRURY, D. R. (1953): Action of Insulin on Volume of Distribution of Galactose in the Body, Amer. J. Physiol., 173, 229. 